\title{
A group decision model for credit granting in the financial market
}

\author{
Paulo Cesar Schotten(D and Danielle Costa Morais ${ }^{*}$
}

\author{
* Correspondence: \\ dcmorais@cdsid.org.br \\ CDSID - Center for Decision \\ Systems and Information \\ Development, Universidade Federal \\ de Pernambuco, Av. Acadêmico \\ Hélio Ramos, s/n - Cidade \\ Universitária, Recife, PE CEP \\ 50.740-530, Brazil
}

\begin{abstract}
Group decision models that contemplate the particularities of the decision-making process help organizations pursue their strategic objectives. In the financial market, the primary interest of organizations consists in ensuring financial returns, which guarantee stability for the organization. This study identifies major problems in the current process of credit granting in the financial market and argues the need for automatizing the organizational decision process while respecting the autonomy of decision-makers. To this end, this study proposes a group decision model based on the Strategic Choice Approach (SCA) for granting credit in a financial market organization. The results show that the adoption of the proposed model offers considerable gains in terms of organizational goals, transparency of the decision-making process, security for decision-makers, and reduction of organizational conflicts.
\end{abstract}

Keywords: Group decision; financial organization, Strategic choice approach, Credit granting, Strategic decision-making

\section{Introduction}

Organizational decisions involve risks, and their complexity increases when a decision requires the participation of several actors. Organizations act competitively in a collaborative environment, and decision-makers need to interact to carry on collective decisions. Many studies (Zhou 2017; Basar et al. 2017; Sirbiladze et al. 2016; Thillaigovindan et al. 2016; Su 2011; Jongsawat and Premchaiswadi 2011; Nutt and John Wiley and Sons 1984; Delbecq et al. 1975) focused on group or individual decision-making, and various analytical procedures to provide methodological support for the decision mechanism were proposed.

Financial organizations have peculiarities, and studies in this field need to focus on their specific needs. The decision-making process of financial entities need to be continuously evaluated and should systematically meet organizational expectations. Financial organizations operate in uncertain environments and act strategically. Their operations involve significant risks, and the decisions made by a group are directly related to financial resources. Wrong decisions immediately affect liquidity and may even compromise organizational competitiveness. The focus of decision-making in a financial organization is related to credit release. Errors of analysis in this process may jeopardize the return of the released capital. Two specific situations may endanger the strategic vision of a company: the lack of a thorough understanding of the consequences of a decision related to the strategic objectives of the organization and

(c) The Author(s). 2019 Open Access This article is distributed under the terms of the Creative Commons Attribution 4.0 International License (http://creativecommons.org/licenses/by/4.0/), which permits unrestricted use, distribution, and reproduction in any medium, provided you give appropriate credit to the original author(s) and the source, provide a link to the Creative Commons license, and indicate if changes were made. 
informal communication that allows employees with greater power or leadership to influence the decision-making process.

Mingers and Rosenhead (2004) discussed the use of problem structuring methods to address the perspectives of multiple actors with conflicting objectives and uncertainties. Several models for structuring decision problems exist: I) SSM - Soft Systems Methodology, discussed by Checkland (2000) and known as a learning system for analyzing complex problems; II) SODA - Development and Analysis of Strategic Options presented by Eden and Ackermann (1998) and considered an approach to help decision makers involved in complex problems find a solution or a set of negotiated solutions; III) VFT - The Value-Focused Thinking, introduced by Keeney (1996), emphasizes the values and goals that decision-makers intend to achieve and provides alternatives for achieving those values; IV) SCA - Strategic Choice Approach, presented by Friend (2004), focuses on the management of uncertainties and strategic situations.

All these models can be applied to complex strategic decisions, but the strategic context in which organizations related to the financial system operate, whose stability depends on political actions and macro influences, suggests the use of the SCA method, also adopted in this study. Friend and Hickling (1997) argued that the SCA helps individuals work together to achieve steady progress in decision-making by focusing on possible ways of managing uncertainty. Since it combines a concern with complexity while emphasizing real-time determination, the SCA has been described as an approach to pressure planning. The SCA model comprises four stages (Friend 2004):

- Modeling: Decision-makers discuss the set of decision problems. At this stage, there are concerns about how choices should be made, how far a decision should be taken, and how decision areas are linked to each other.

- Design: Stakeholders debate whether there are sufficient options or technical and policy constraints that prevent a combination of decision area options. This combination of feasible decision options define the alternatives.

- Comparison: Decision-makers discuss how the implications of different alternatives should be compared. The actors consider various criteria, or areas of comparison, and discuss how the evaluations of alternatives should be performed.

- Choice: Characterized by the focus on the commitment of the actions envisaged in the viable alternatives over time. The concern in this phase is on how the future process can be managed when faced with uncertainties.

The results of the SCA clarify how organizational objectives are achieved, thus providing transparency in the process and security to decision-makers, who are induced to reflect on the consequences of their action. As a result, organizational conflicts are minimized. Based on those advantages, the SCA can be successfully applied to different contexts such as public policy planning (Friend et al. 1974); managing uncertainty (Sutton et al. 1986); motivational appeals (Shelby 1991); policy alternatives for the transportation, storage, and distribution of liquefied gas (Friend 1992); urban planning (Khakee and Strömberg 1993); political change (Collier and Norden 1992); international relations (Lake and Powell 1999); community planning for rural education (Friend 2004); location and marketing conflicts (Friend 2004); transformation of industrial relations (Leggett 2005); water resources planning (Levino and 
Morais 2013); spatial planning (Diller and Oberding 2017), and architectural design (Todella et al. 2018).

Focusing on the needs of organizations that operate in the financial market, which act in a strategic environment, this study proposes a group decision model for a financial organization. The proposed approach aims to evaluate the uncertainties of the process and assist decision-makers with the provision of information and guidance, simplifying the decision-making process, and allowing actors to adopt a broad and systemic view of the organizational objectives. In doing so, the proposed approach applies a strategic decision-making model without changing the way that the organization works but contributing to the result with an alternative approach to decision-making.

The remainder of this paper is organized as follows. Section 2 provides a brief literature review of credit granting in the financial market. Section 3 presents a case study in a Brazilian Financial organization that served as an application for the proposed model. Section 4 presents the proposed group decision model for credit granting. Section 5 provides our concluding remarks.

\section{Credit granting in the financial market}

Zopounidis and Doumpos (2002) found that, during the last decades, the globalization of financial markets, the intensifying competition among firms, financial institutions, and organizations as well as the rapid economic, social, and technological changes have led to increasing uncertainty and instability in the financial and business environments. Zopounidis et al. (2015) argued that the increasing complexity and volatility of the global financial system determined the increasing use of sophisticated analytic techniques for analyzing financial data and supporting financial decisions.

Angilella and Mazzù (2017) addressed the difficulties of small and medium-sized enterprises in accessing finance options and recognized that the financial system (banks and institutions) play an essential role in the provision of credit. According to these authors, the way the system is being administered leads to the tightening of rules and automatically impairs access to credit to companies, which significantly affects their innovation and development capacities. The decisions of credit release evolve based on statistical, operational, and technical surveys by using the information retained by companies. In the authors' conception, these techniques are not entirely appropriate for evaluation because they disregard important aspects and often fail in considering relevant information and limitations imposed by the system itself.

The modeling of financial issues according to Zopounidis and Doumpos (2002) is based on a different logic, which takes into account the existence of multiple criteria, the conflicts among criteria, the complex, subjective, and poorly structured nature of the evaluation process, and the characteristics of financial decision-makers. These authors distinguished three reasons that may lead to a change in the modeling of financial problems, namely: a) the formulation of the problem, in the search of an optimal decision, by financial decision makers involved in a limited and problematic environment, often irrelevant to the decision itself; b) human involvement in decision-making, which takes into account preferences, experiences, and knowledge; c) the illusion of optimality in decision-making, since many criteria must be considered in the choice of investment projects and risk assessment. 
Mustafá et al. 2018described financial innovation as an essential element of monetary action and argued that financial development generated systemic changes in the financial market through the improvement of financial services. Lin et al., 2015 focused on the advances in technology, stating that, in the last two decades, Internet technologies, such as cloud computing, mobile communications, social media, and big data analytics, have generated tremendous changes in our society and reshaped the business in various industries. The mushrooming innovation in the financial area nurtured by information and communication technologies determined the advent of the internet finance era. Arthur (2017) argued that the power of financial innovations affects societies at the global and intergenerational levels and questions their responsible emergence in society can be assured, thus addressing a concern regarding innovation. This issue requires a thorough understanding of how innovation occurs and is conducted in practice. Caiani et al. (2016) highlighted the importance of analyzing the economic environment to formulate a model for decision-making, which considers all aspects that influence the decision-making process, and advocate the need for a comprehensive study of macroeconomic systems.

Zopounidis and Doumpos (2002) pointed out that the most common approach to dealing with credit risk is to develop appropriate models that classify companies into predefined groups and suggest the application of a multicriteria decision-making method. Zopounidis et al. (2015) also defended this application and suggested the importance of understanding how decisions in financial operations are made in practice. The author argued that, compared with different theories, the application of a multicriteria method meets various perspectives and integrates different elements of financial operations. Regarding the application of a multicriteria decision-making method in the financial market, Angilella and Mazzù, (2017) investigated the main shortcomings of the existing models and showed that these methodologies might help decision-makers in the choice and classification of problems.

Zopounidis and Doumpos (2002) argued that the MCDA (Multiple-Criteria Decision Analysis) allows decision makers to actively participate in the financial decision process by supporting the understanding of the peculiarities and unique characteristics of real-world problems. The main advantages of the application of a multicriteria decision method in financial decision-making were presented by Zopounidis (1999) and can be summarized as follows: (1) the possibility of structuring complex problems of evaluation, (2) the introduction of quantitative criteria and financial and qualitative indices in the evaluation process, (3) transparency in the evaluation, which allows a clear argumentation in the financial decisions, and (4) the introduction of sophisticated, flexible, and realistic scientific methods in the financial decision-making process.

\section{The case of a Brazilian financial organization}

The object of study is a credit cooperative characterized by free admission of associates, located in the State of Paraná, Brazil. The group decision system adopted in the organization is focused on the credit analysis process and is called the Electronic Decision Process. Operationally, the credit decision analysis process goes through a series of steps and, depending on the circumstances and the credit rating, the Unit Committee or the Regional Review Committee makes a decision. 
The Unit Committee usually consists of three people. The members are chosen within the organizational structure and, although they can vary from unit to unit, major or minor, they are chosen from their peers. The members of this committee are the Manager of the Service Unit, the Business Manager, and another member who can be an assistant, cashier, or another employee who, as stated before, exclusively depends on the structure of the agency. The Regional Committee is also composed of three members linked to the Regional Superintendence, whose function is to make decisions. The members of the Regional Review Committee are chosen from the representative positions and generally are the Regional Administrative and Financial Manager, the Operations Director, and another member to be chosen from the Regional Development Manager, the Controller, Executive Director or even the President or Vice President.

Both committees apply the same decision-making process. Therefore, the study of this process focuses on its structure regardless of the choice of the committee The basic itinerary, shown in Fig. 1, begins with the request for credit from the unit. The group decisions occur at the level of Committees, presented in the figure as Collaborative Network Level Committee UA (Unity of Attendance) and Collaborative Network Level Regional Committee.

Group decisions are made by the organization at the committee level and can be at the level of the Service Unit or Regional Level, as indicated in the process by the arrow. Based on the information transmitted by the current system, decisionmakers individually act in the voting process by indicating how favorable they are to the process in progress. The decision ruling in the process has to be unanimous to ensure the return of capital due to the risk of operations in the financial system.

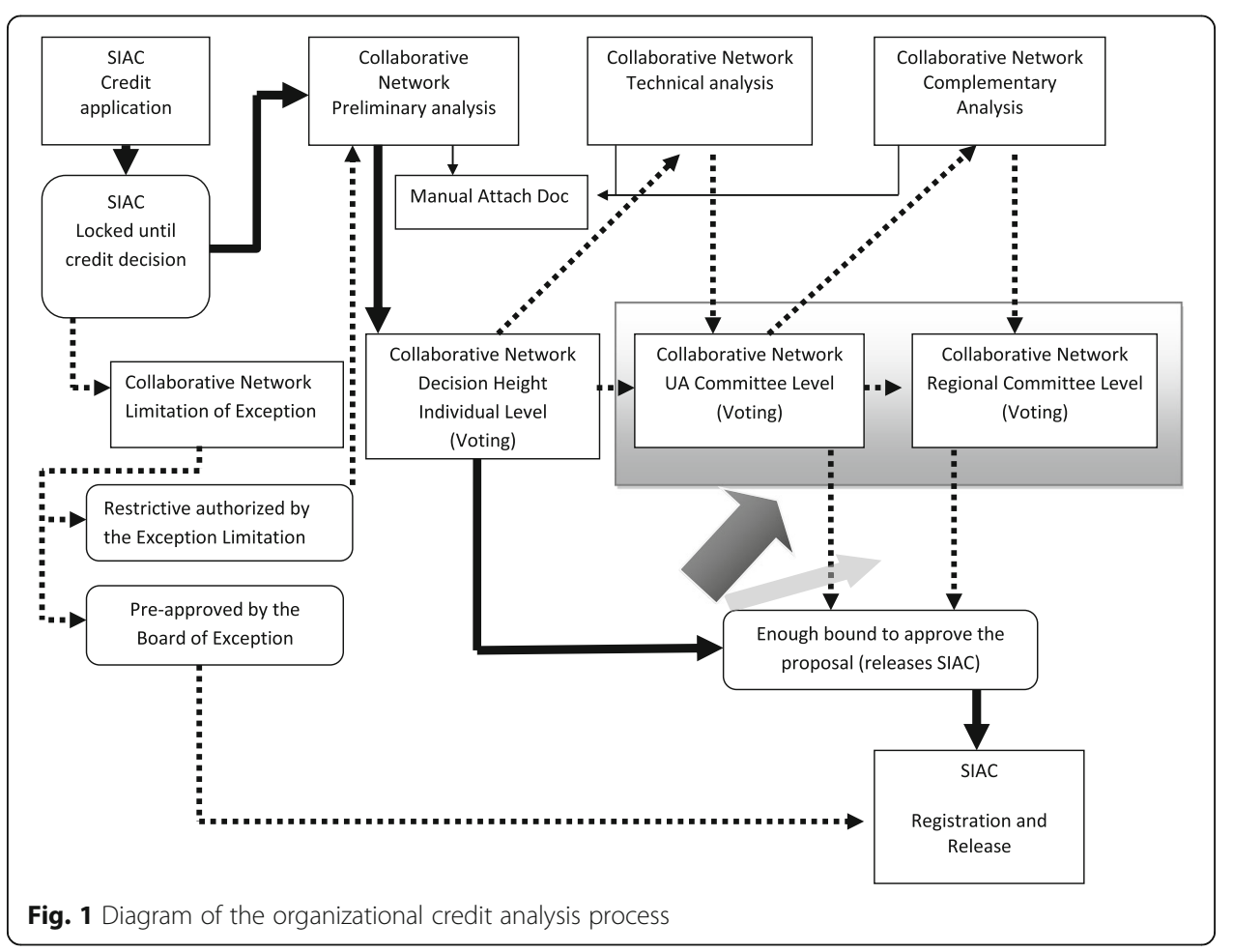


To be approved, a process cannot receive negative feedback from any of the decision-makers.

The process received by decision-makers is composed of a preliminary opinion drafted by officials who occupy various positions within the Service Unit and were assigned to this task. In this step, consideration is given to a set of elements, summarized by the considerations of the proposer's account manager: the tenderer's financial standing, a market analysis, the relationship and management of the accounts, the analysis of their strengths and weaknesses, and the conclusion.

It is worth noting that the system presents, in this preliminary opinion, a score based on the Balanced Scorecard, whose result indicates the scale of the risk of the movement. Other sources of information that are linked to the system for formulating the preliminary opinion are the Credit System of the Central Bank of Brazil and the Credit Protection System (SPC).

The Balanced Scorecard (BSC) is a management system that organizations use to communicate what they are trying to accomplish, align the daily work that everyone is doing with strategy, prioritize projects, products and services, measure and monitor progress in strategic goals. [...] Among other functions, one of them is measures (or key performance indicators) [...]. BALANCE SCORECARD INSTITUTE ( 2017).

An essential point in the decision-making process is the access to the system because, for some higher positions in the organizational structure, this access can be done through an external network, using VPN. In this case, the application of information technology in the process of group decision-making entails an electronic decision process. This observation is in line with the proposal of Adla et al. (2010), which suggest that virtual platforms help significantly improve strategic decisions.

For decision-making purposes, decision-makers depend on reports that present data such as information from buyers and guarantors, the history in the financial credit system, cash flow from the physical or legal tenderer, and, finally, transactions. All decision-makers have the same weight in the voting procedure, and the calculation process is automatic in the system. When decision-makers are asked about how they analyze the process and practices of decision-making, the results show the absence of a standard of action and that each member acts in complete autonomy. Therefore, decisions can be based on data or be affected by personal relationships.

The current flow of the group decision-making process is shown in Fig. 2. Once the process is received via the system, decision-makers need to individually analyze the process and documentation presented and, based on their perception of these documents, decide whether they are favorable or not to the approval of the credit release. Since there are three decision-makers, each one individually decides, and the ruling must be unanimous. To be approved, the process must receive the favorable vote of all the three decision-makers.

Two major problems emerged from the study of the organization's decision-making process. The first issue is related to the consequences of the decision since the current system does not motivate decision-makers to assess the consequences of their 


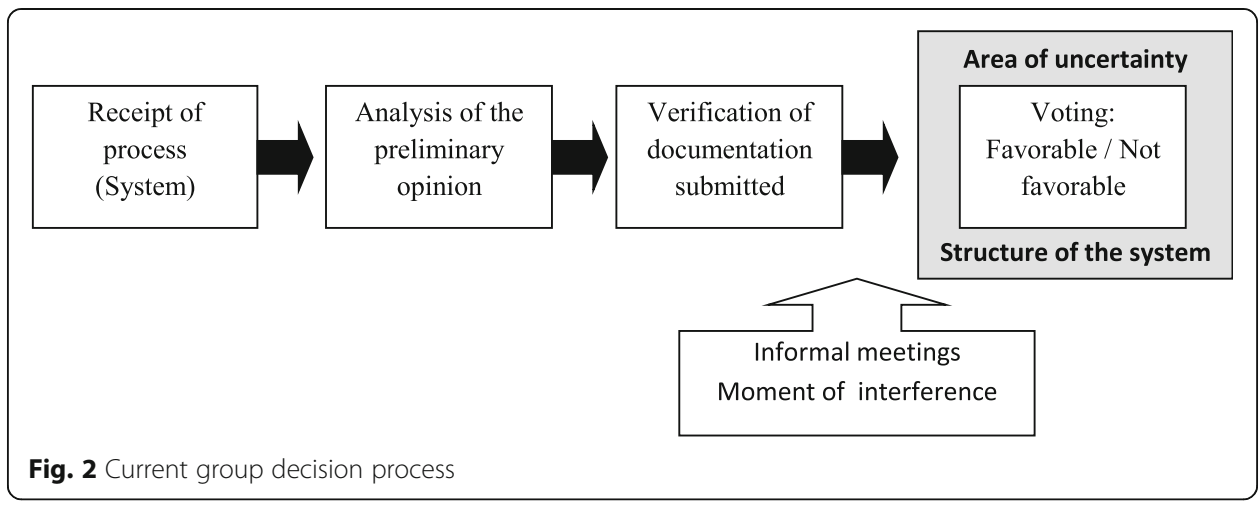

decisions in relation to the strategic thinking of the organization. A second difficulty observed is the fact that, in some situations, as shown in Fig. 2, conversations take place between the members of the analysis committees, who discuss the proposal or preliminary/technical opinion, even though this is not required in the organization's decision-making system. In this case, there is no control over what happens in informal meetings, which may lead to a paradigm of group decision-making influenced by the pressure or leadership. In other words, in such situations, the decisions of the members of the committees may be influenced by the one who holds the highest position in the organization by force of pressure or even by the leadership of any of the members.

The credit analysis decision is a potential generator of conflict both in the relationship between the proposer and the institution, usually resulting from the delay in the process and/or dissatisfaction with the result of the operation, and in the relationship between the members of the organization committees because dissatisfaction with the result in a given vote may upset the members that exert greater pressure. This tends to charge other members and creates a relationship of dependency for new cases that will arise in the future.

In line with this assumption, an ideal model for the organization should solve or at least minimize the impact of these drawbacks of the current system. The decision-making process should visualize the result based on the strategic objectives of the organization, direct the individuals to a personal analysis without interferences of other members involved the process, and be composed of clear rules that minimize organizational conflict. The model presented in the next section seeks this balance for the group decision-making process.

\section{Proposed group decision model}

The setting presented in this section represents a strategic situation in a context characterized by uncertainty, in which planning and action need to maintain a long-term focus on the survival of the organization, under continued pressure on the market. It has already been mentioned that the ideal model needs to consider the uncertainties of the lending process, minimize conflicts, direct decision-making toward the strategic objectives of the organization, and limit the influence of decision-makers with greater power to avoid losing the characteristics of a group decision. 
To implement the proposed model, the authors first contacted the executive members of the organization to present the objectives and potential benefits of the proposed decision-making process, which may help the company pursue its strategic objectives. Once the project has been approved by the company along with the Executive Director, an initial awareness of the process has been established among the decision-makers. This step has been coordinated by the Executive Director, who, through internal communication and presentation in a meeting, clarified to the members of the organization the purpose of the work and how it would be developed within the organization.

The initial phase of the credit granting process has not been altered, as shown in Fig. 2. The proposed model aims to formalize informal meetings for achieving the specific strategic objectives of the organization. The first phase of the proposed approach is the organization of a workshop to clarify the strategic choice approach. The second phase focuses on the decision-making process and considers its operational aspects and, more specifically, the question of achieving strategic objectives and limiting influences in the process. Therefore, the argument that better justifies the application of the proposed model is the systematization of the decision-making process, for providing security to the process and serving as a guide to the strategic objectives established by the organization.

The phases of the proposed group decision model for this organization are presented in Fig. 3, which summarizes the current decision-making process of the organization, the complex risk of the operations, and the uncertainties to which the financial system is exposed.

\section{Workshop}

The workshop was fully interactive and based on the SCA, and had the effective participation of organization members related to the decision-making process, such as the Executive Director of the organization, a member of the business management from the agency, a member of the analysis process, and a credit analyst. The workshop was

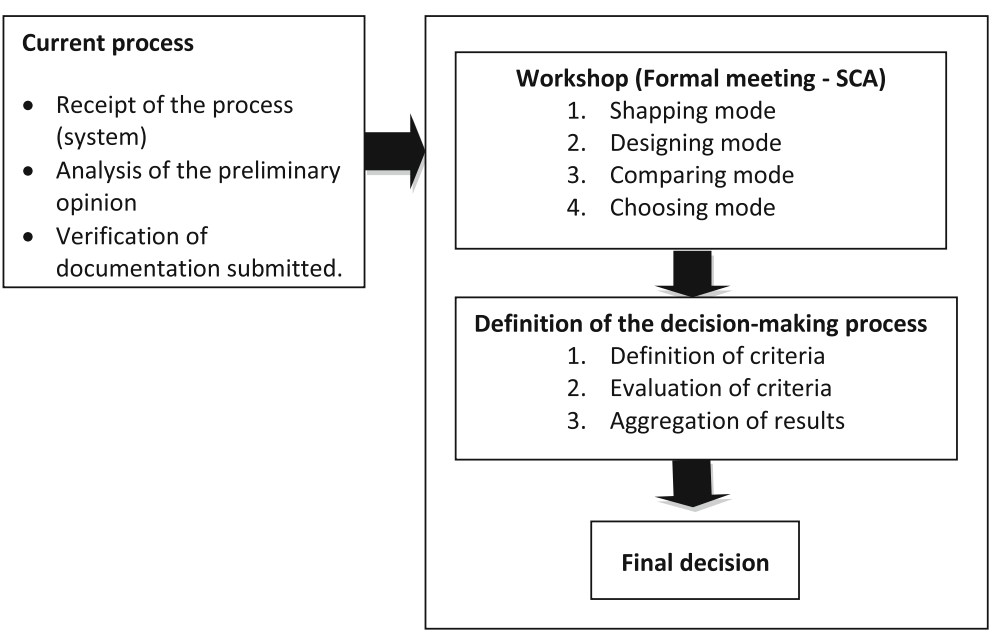

Fig. 3 Phases of the proposed group decision model 
directly scheduled with the Executive Director, who invited other members to participate. The objectives and the expectations of the model were introduced, raising awareness of the importance of individual contributions and emphasizing the strategic aspects of the decision process. All members were free to express their opinions and contribute to the development and understanding of the problem. The Executive Director is directly responsible for the strategic objectives of the organization and has significant knowledge of the environment and legal aspects of the credit granting process. Therefore, his preferences were used in the second phase.

\section{Shaping}

In this stage, the concern is the set of problems presented, and the debate seeks to point out how decisions are connected. This part of the process consists of identifying decision areas. The decision areas were defined by the workshop participants, as mentioned in paragraph 4.1. The debates sought to define how choices are made, what decisions will be made, how to link decisions, and, if necessary, broaden the focus on divisions to improve management.

The form of data collection continued to be group discussion, and the answers obtained were the result of group consensus. The focus of the work was clarified, and the initial concerns were to maintain the original idea of the work and focus on the relationships that are involved in the group decision and credit analysis. The decision areas that resulted from the group debate are presented in Table 1.

To guarantee greater visibility to the process of interaction and generate alternatives, we identified activities directly linked to the credit analysis process and ancillary activities (Fig. 4), which are generated as a result of the operation. We classified all actions as decision-making activities (Strategic Decision, Communication, and Autonomy) and ancillary activities (Bureaucracy and Satisfaction areas).

A concern regarding the decision areas arose regarding the involvement and the level of understanding of the decision-makers who took part in the process. It is opportune to clarify that, in the development of the method and the format of the workshop, all the strategically involved members discussed the five decision areas and all had full knowledge and understanding of the relationships among the decision areas. The facilitator who conducted the workshop raised a question for discussion, allowing everyone to contribute to the development of the method. It is also worth noting that the proposed method, in its operational aspects, leads decision-makers to carry on individual analysis, and the group decision is the result of the aggregation of individual contributions. Each decision-maker is also required to understand the strategic objectives, the criteria, and the relationships among the decision areas. To this end, the organization

Table 1 Decision areas

\begin{tabular}{ll}
\hline Decision Área & Label \\
\hline What is the objective regarding the service to the proponent? & Strategic \\
How should communication between decision makers be? & Communication \\
What is the autonomy of decision-makers in the credit analysis process & Autonomy \\
How bureaucratic can the operation be? & Bureaucracy \\
What is the expected level of satisfaction of the proposers? & Satisfaction \\
\hline
\end{tabular}




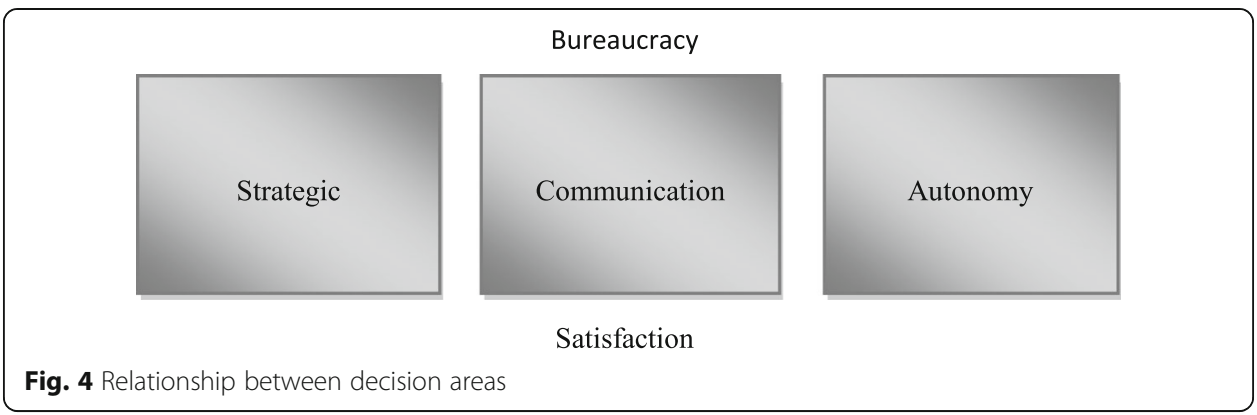

must apply continuous flow training targeting all the decision-makers involved in the credit analysis process.

\section{Design}

The next step of this process is to define the decision options. The procedure, in this phase, is similar to that adopted in the previous step. The decision options, once defined, will serve as a basis for analysis. The definition of the decision options is the result of the discussion carried on by the strategic members of the organization, who participate in workshops within the organization, chaired by the Executive Director. The authors of this study acted as facilitators. From this group discussion, where everyone could contribute to the process with his/her perception, the decisions options were established by consensus and applied in the Design stage. The workshop participation in this stage and the search for a consensus are precious elements because they assure that all participants aggregate their knowledge and learn within the process, thus assuring that the focus remains on the strategic objectives of the organization. The primary objective in the debates was to create a set of acceptable solutions, and the main task of the group was to formulate possible actions, analyze the feasibility of each course of action, define whether the set of actions was sufficient or not, and what restriction techniques or policies influenced the courses of action. After the relevant analyses, the decision options were defined for the decision areas, as presented in Table 2.

Once the decision options have been defined, the proposed method allows elaborating a decision tree that shows the decision alternatives obtained through the comparison and combination of the strategic options for the decision areas. In this case, the decision tree was defined as shown in Fig. 5.

Table 2 Decision options

\begin{tabular}{|c|c|c|}
\hline Decision Área & Decision Options & Label \\
\hline $\begin{array}{l}\text { What is the objective regarding the } \\
\text { service to the proponent? }\end{array}$ & $\begin{array}{l}\text { Reference in the Credit Granting Process. Ensuring } \\
\text { achievement of organizational objectives }\end{array}$ & Strategic \\
\hline $\begin{array}{l}\text { How should communication } \\
\text { between decision makers be? }\end{array}$ & $\begin{array}{l}\text { Fully computerized and independent decision. Fully } \\
\text { computerized, with the possibility of personal contact } \\
\text { for decision. Not computerized and very close contact } \\
\text { between decision makers. }\end{array}$ & Communication \\
\hline $\begin{array}{l}\text { What is the autonomy of decision- } \\
\text { makers in the credit analysis } \\
\text { process }\end{array}$ & $\begin{array}{l}\text { Total autonomy of each decision maker. Autonomy } \\
\text { limited to range of values. Without autonomy. }\end{array}$ & Autonomy \\
\hline
\end{tabular}




\begin{tabular}{|c|c|c|c|}
\hline Strategic & Communication & Autonomy & Identifier \\
\hline \multirow{9}{*}{$\begin{array}{l}\text { Reference in the process of } \\
\text { Credit Granting }\end{array}$} & \multirow{3}{*}{ Computerized and independent } & Total autonomy of each decision maker & A \\
\hline & & Autonomy limited to range of values & B \\
\hline & & Without autonomy & c \\
\hline & \multirow{3}{*}{ Computerized, little contact } & Total autonomy of each decision maker & D \\
\hline & & Autonomy limited to range of values & $\mathrm{E}$ \\
\hline & & Without autonomy & $\mathrm{F}$ \\
\hline & \multirow{3}{*}{ Not computerized, lots of contact } & Total autonomy of each decision maker & G \\
\hline & & Autonomy limited to range of values & $\mathrm{H}$ \\
\hline & & Without autonomy & 1 \\
\hline \multirow{9}{*}{$\begin{array}{l}\text { Ensuring achievement of } \\
\text { organizational objectives }\end{array}$} & \multirow{3}{*}{ Computerized and independent } & Total autonomy of each decision maker & $\mathrm{J}$ \\
\hline & & Autonomy limited to range of values & $\mathrm{K}$ \\
\hline & & Without autonomy & L \\
\hline & \multirow{3}{*}{ Computerized, little contact } & Total autonomy of each decision maker & M \\
\hline & & Autonomy limited to range of values & N \\
\hline & & Without autonomy & 0 \\
\hline & \multirow{3}{*}{ Not computerized, lots of contact } & Total autonomy of each decision maker & $\mathrm{P}$ \\
\hline & & Autonomy limited to range of values & Q \\
\hline & & Without autonomy & $\mathrm{R}$ \\
\hline ig. 5 Decision Tree & & & \\
\hline
\end{tabular}

\section{Comparison}

Using the alternatives defined in the Design mode, in the next step, the areas of comparison, also called criteria of evaluation of alternatives, need to be defined. To facilitate the understanding of the model, the comparison stage was described in the workshop by the strategic members of the organization. The group provided a definition of the comparison areas and limits, obtained through discussion and presentation of ideas until a consensus was reached. Although the process has been developed within the workshop, for the sake of the analysis, the Executive Director preferences were applied because he/she is responsible for the strategic decisions of the organization and knows the environment and the rules of the process. After this, four areas of comparison were identified, as presented in Table 3, together with the order of importance of each of the areas established by the group and its respective decision rule.

The next step in the group decision was to identify an evaluation scale that would be applied to the organizational problem, as presented in Table 4.

Once the scoring scales were defined by the group, the next step consisted in adding up the score of each decision option, following the path established in the decision area. The final score obtained is reported in Table 5.

Table 3 Comparison areas

\begin{tabular}{llll}
\hline Order of importance & Comparison Area & Label & Comparison rule \\
\hline $1^{\text {a }}$ & Credit Security & Safety & The greater the number of symbols, the better \\
$2^{\text {a }}$ & Response Time & Response Time & The greater the number of symbols, the worse \\
$3^{\text {a }}$ & Community Service & Attendance & The greater the number of symbols, the better \\
$4^{\text {a }}$ & Bureaucratic process & Bureaucracy & The greater the number of symbols, the worse \\
\hline
\end{tabular}


Table 4 Score for decision areas

\begin{tabular}{|c|c|c|c|c|}
\hline \multirow[t]{2}{*}{ Decision options } & \multicolumn{4}{|c|}{ Comparison Areas } \\
\hline & Attendance & Safety & Bureaucracy & $\begin{array}{l}\text { Response } \\
\text { Time }\end{array}$ \\
\hline Reference in granting of credit & $X X X X$ & $X X X X$ & & \\
\hline Achieving organizational goals & $X X X X$ & $X X X X$ & & \\
\hline Fully computerized and independent decision & $X X X X$ & $X X X$ & $x$ & $x$ \\
\hline $\begin{array}{l}\text { Fully computerized, with the possibility of personal contact } \\
\text { for decision }\end{array}$ & $X X X$ & $X X X X$ & $x$ & $X X X$ \\
\hline $\begin{array}{l}\text { Not computerized and very close contact between decision } \\
\text { makers. }\end{array}$ & $x$ & $x$ & $X X X X$ & $X X X X X$ \\
\hline Total autonomy of each decision maker & $X X$ & $x$ & $x$ & $x$ \\
\hline Autonomy limited to range of values & $X X X X$ & $X X X X X$ & $X X X$ & $X X X$ \\
\hline Without autonomy. & $x$ & $x$ & $X X X X X$ & $X X X X X$ \\
\hline
\end{tabular}

Due to the large number of alternatives, the number of options to be evaluated needs to be reduced. To this end, a filter was created by the group for defining minimum scores for the areas of comparison. This score is shown in Table 6.

When the filter was applied, four alternatives that fit the selection process were selected, as shown in Table 7.

\section{Choosing}

The next step is the choice determination and is carried on by comparing alternatives. This stage is the result of the application of the method over the parameters established in the workshops by the members of the strategic areas of the organization. Once

Table 5 Scoring alternatives for comparison

\begin{tabular}{lllll}
\hline Identifier & Attendance & Safety & Bureaucracy & Response Time \\
\hline A & 10 & 8 & 2 & 2 \\
B & 12 & 12 & 4 & 4 \\
C & 9 & 8 & 6 & 6 \\
D & 9 & 9 & 2 & 4 \\
E & 11 & 13 & 4 & 6 \\
F & 8 & 9 & 6 & 8 \\
G & 7 & 6 & 5 & 6 \\
H & 9 & 10 & 7 & 8 \\
I & 6 & 6 & 9 & 10 \\
J & 10 & 8 & 2 & 2 \\
K & 12 & 12 & 4 & 4 \\
L & 9 & 8 & 6 & 6 \\
M & 9 & 9 & 2 & 4 \\
N & 11 & 13 & 4 & 6 \\
O & 8 & 9 & 6 & 8 \\
P & 7 & 6 & 6 & 6 \\
Q & 9 & 10 & 8 & 8 \\
R & 6 & 6 & 10 & 10 \\
\hline
\end{tabular}


Table 6 Score limits for the evaluation of alternatives

\begin{tabular}{ll}
\hline Labels & Choice \\
\hline Attendance & 9 \\
Safety & 9 \\
Bureaucracy & 5 \\
Response Time & 4 \\
\hline
\end{tabular}

defined by consensus the decisions areas, the relationships among them, and the decision options, the next step was to establish the possible paths and limits for the evaluation of alternatives. Then, the choice is developed by analyzing the result.

Considering the results reported in Table 8 and taking into account the strategic vision of the organization in relation to credit granting, two points can be highlighted regarding the selected labels. Once all the rules of choice have been met, the security of the credit granting and the response time for the proponent become the focus of attention.

The characteristics of the proposed scenario lead us to consider strategic paths for the organization based on the security label since all the selected alternatives presented the same evaluation with respect to the response time. Therefore, there are only two alternatives for the organization, namely, B and K. The paths are shown in Table 8 .

These two paths indicate that the decision must be computerized and independent and assume that the autonomy of decision-makers should be limited to intervals of values. The two paths differ in the strategic area: path B is a reference in the process of granting credit, while path $\mathrm{K}$ relates to a strategy to achieve the organizational objectives.

Therefore, the analysis result suggests that to achieve the strategic objectives of the organization, the organizational decision needs to be computerized and independent with autonomy limited to a range of values. The first phase of the model leads to concrete gains for the organization and directly addresses the issues of the process currently adopted. In particular, the proposed method:

a) guarantees the achievement of the organizational objectives when reflecting on the strategic needs of the organization and comparing them with its internal and external environment;

b) guarantees transparency in the credit analysis process;

c) provides support for decision-making;

d) induces decision-makers to reflect on the consequences of their actions in relation to the organizational objectives;

e) provides greater security to the decision maker;

f) minimizes organizational conflicts;

Table 7 Selected alternatives

\begin{tabular}{lllll}
\hline Identifier & Attendance & Safety & Bureaucracy & Response Time \\
\hline B & 12 & 12 & 4 & 4 \\
D & 9 & 9 & 2 & 4 \\
K & 12 & 12 & 4 & 4 \\
M & 9 & 9 & 2 & 4 \\
\hline
\end{tabular}


Table 8 Final alternatives

\begin{tabular}{llll}
\hline Identifier. & Strategic & Communication & Autonomy \\
\hline B & $\begin{array}{l}\text { Reference in the Credit Granting } \\
\text { Process }\end{array}$ & $\begin{array}{l}\text { Ensuring achievement of } \\
\text { organizational objectives }\end{array}$ & $\begin{array}{l}\text { Autonomy limited to } \\
\text { range of values }\end{array}$ \\
K & $\begin{array}{l}\text { Ensuring achievement of } \\
\text { organizational objectives }\end{array}$ & $\begin{array}{l}\text { Ensuring achievement of } \\
\text { organizational objectives }\end{array}$ & $\begin{array}{l}\text { Autonomy limited to } \\
\text { range of values }\end{array}$ \\
\hline
\end{tabular}

g) reduces the influence of other agents on the decision-maker at the time of evaluation and decision-making.

\section{Definition of the decision-making process}

After the workshop, it was agreed that the decision-making system should be computerized and independent. Then, the process focused on addressing the drawbacks pointed out in the case description, more specifically, the lack of consideration of the consequences of decision-making and the possible interference in the voting process or monopolization by those who hold the highest position by means of pressure or leadership.

\section{Definition of criteria}

The definition of criteria involves the format of an operational model of decision-making that addresses these needs. The set of strategies to be compared is restricted to a single area of decision-making, linked to credit analysis and financial management. The process comprises two aspects: the effects of the actions in each of the criteria or areas of comparison (valuation of the alternatives) and the evaluation of the consequences of these alternatives. In this stage, a multicriteria method can be applied.

Multiple decision-making methods (MCDM) can help managers achieve important decisions that cannot be determined directly. (Lin and Lee 2010)

A process for this stage and the following organizational analysis are defined by reviewing the existing structure. This step aims to reduce the uncertainty of the decision-making process, help decision-makers consider the strategic consequences of their decisions, reduce conflicts, and limit influences within the organization. It is worth mentioning that each decision-maker carries on individual evaluations, and the final group decision is the result of the individual analyses of all decision-makers.

This process leads the decision-maker to reflect on the consequences of each decision and the impact of pre-established criteria for the decision through the evaluation of alternatives. In this context, decision-makers have a direction of analysis that helps them anticipate the consequences of their decisions. In addition, being an already defined tool, with clear rules of decision, the proposed approach eliminates the possibility of informal meetings between the decision-makers involved in the process, thus resulting in the reduction of organizational conflicts.

In the proposed structure, the alternatives for the decision-making are the financial score and the applicant's score obtained as a result of the Balanced Score Card, an instrument already used by the organization. Indebtedness reflects the debts contracted and outstanding in the name of the claimant, while the ability to pay considers the 
relationship between the income and commitments of the claimant and the limits of income commitment. The equity analysis addresses the personal property on behalf of the applicant that can serve as a guarantor or even support the payments, even if he/ she is not considered a guarantee of payment.

Other points observed in the analysis refer to the history of operations within the organization, namely, the active participation and punctual payments in previous operations, assets that guarantee this specific operation, the professional activity performed (whether risky or not), and the relationship between the candidate and the unit and/or organization. The aggregation of the results would automatically be based on rules established by the organization, defined and introduced by the system, which, in turn, generate the final result. From the operational point of view, the analysis interface would have the format shown in Fig. 6.

\section{Evaluation of criteria}

The director and the technician defined as a decision rule that each decision-maker would individually score 1 to 5 alternatives according to the caption and table presented (Fig. 6). In this stage, the group established that all alternatives would have the same degrees of importance, and the calculation of the result would be the sum of the weights divided by the number of the decision-makers. This simple average represents the final evaluation result.

\section{Aggregation of results}

To obtain the final result of the decision group, aggregation is carried on by using an additive model and considering all alternatives and evaluators with the same weight. Due to personal availability, three members of the Unit Committee, supervised by the Credit Analysis Technician, participated in the process, thus forming the ruling group.

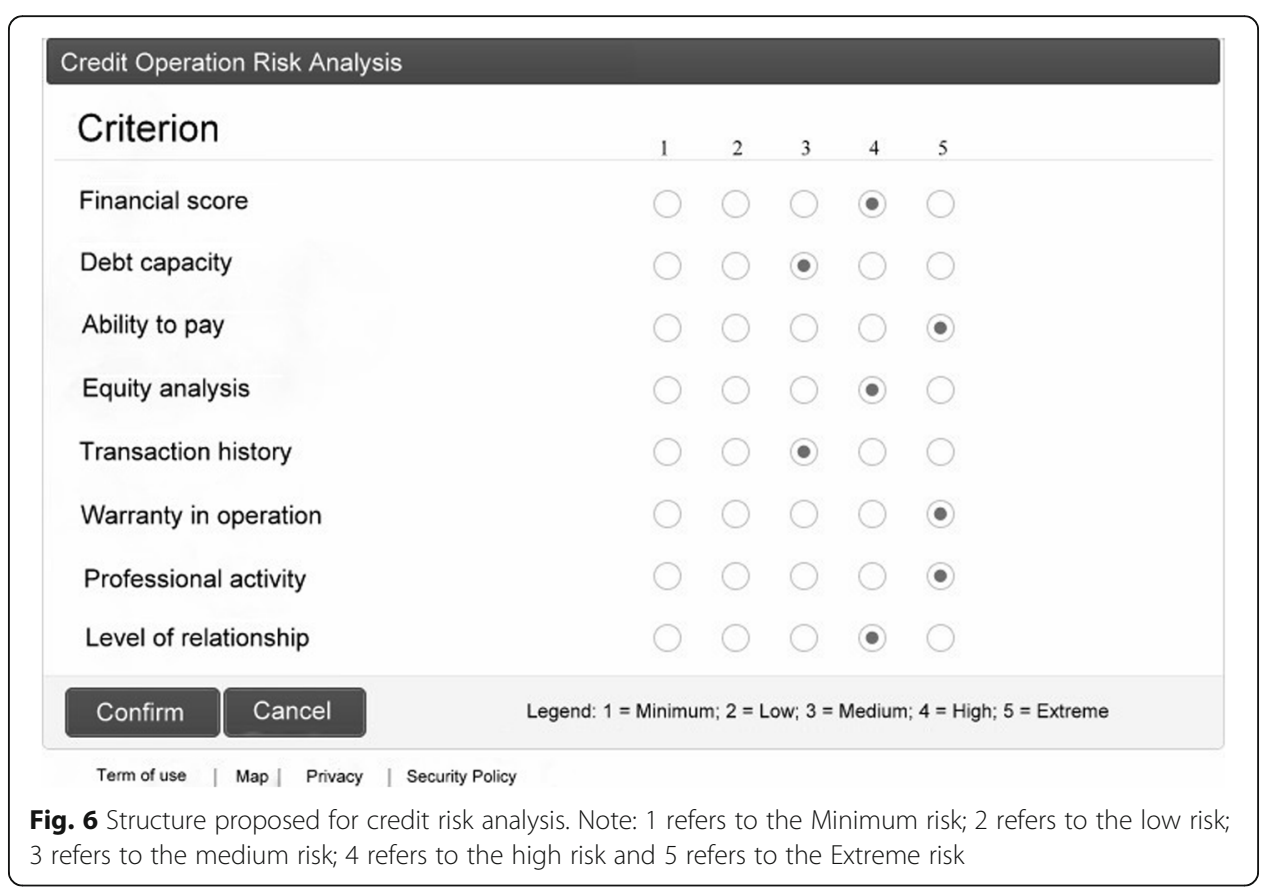


The suggested model was applied to 13 random cases analyzed in the last 15 days, chosen by the technician responsible for the credit in the organization. The model applied in the simulation was developed based on this study, and the future application of this structure will depend on the decision of the organization itself. The final result, for analysis purposes, was the mean of the scores of the three evaluators, obtained from the application of formula 1 .

$$
P=\frac{\sum_{j=3}^{n} i}{j}
$$

where:

$P=$ final score;

$i=$ decision maker $(i=1,2,3)$;

$j=$ number of decision-makers participating in the evaluation process.

The decision rule adopted for the simulation was the following:

- Proponent with a score of up to 20 points in the sum of the analyses: credit approved;

- Proponent with a score of up to 20 points and more than one extreme risk assessment: technical analysis;

- Proponent with a record of risk analysis equal to 5, score higher than 20 points in any of the analysis criteria: forwarded to technical analysis;

- Proponent with a score higher than 30 points in the evaluation of the decisionmakers corresponds to refused credit and would automatically return to the agency to obtain additional guarantees or even refuse the credit.

The proposed analysis was applied, and the answers obtained are presented in Table 9.

The application of the suggested structure would not, in theory, alter the results of the organization's regular operations. However, the gains in terms of security of the technical analysis and operational ease increase the reliability in the operations carried

Table 9 Application of the analysis process in real cases related to the organization

\begin{tabular}{lllll}
\hline Case & Result in organization & $P=$ Final score & Extreme risk of occurrence & Result of suggested structure \\
\hline 1 & Approved & 24 & 1 alternative & Technical analysis \\
2 & Approved & 22 & 2 alternative & Technical analysis \\
3 & Approved & 24 & 1 alternative & Technical analysis \\
4 & Not approved & 32 & 4 alternative & Not approved \\
5 & Approved & 25 & 1 alternative & Technical analysis \\
6 & Approved & 24 & 1 alternative & Technical analysis \\
7 & Approved & 15 & 0 alternative & Approved \\
8 & Approved & 21 & 1 alternative & Technical analysis \\
9 & Approved & 24 & 2 alternative & Technical analysis \\
10 & Approved & 22 & 1 alternative & Technical analysis \\
11 & Approved & 16 & 1 alternative & Approved \\
12 & Approved & 20 & 2 alternative & Technical analysis \\
13 & Approved & 23 & 2 alternative & Technical analysis \\
\hline
\end{tabular}


on by the individual decision-maker and his/her response. In addition, it guarantees that the objectives of the organization will be achieved.

\section{Final decision}

In line with the definition and evaluation of the proposed criteria and the aggregation of individual results, we obtained the final result of the group analysis. After discussion and comparison with the organizational strategic objectives, all members involved in decision-making agreed that the submitted credit review process meets the needs of the organization and may help achieve its strategic organizational goals.

\section{Discussion and implications}

The proposed structure provides organizations with a tool to respond to their fundamental needs, identified as the typical problems of decision-making. When various alternatives are observed, the proposes strategy induces a reflection on the strategic consequences of organizational decisions on their strategic objectives. This helps decision-makers interpret the decision process and consequences by highlighting decision alternatives. As a result, decision-making is not the product of dependency or perception or relationships but follows a well-defined rule that assesses the alternatives in relation to the result.

Once the path and the alternatives have been defined, informal meetings are no longer justified, thus limiting the influence of superiors in the management process or those with greater leadership. Well defined rules and limited pressure within the organization, obtained by adopting a structured and well-grounded stance in the rules mentioned above, tend to minimize organizational conflicts, not giving the organization members any reason for questioning the result.

The primary gains for the organization induced by the proposed model can be summarized in the achievement of its organizational objectives, the transparency of the credit analysis process, the security and clear direction for the decision-maker, who is also induced to reflect on the consequences of each decision. In addition, the proposed model minimizes conflicts and reduces influences in the decision-making process by higher levels employees or those exercising leadership in the organizational structure.

Some implications in the adoption of this structure have a direct impact on the field of action of senior management. Therefore, it is essential to draw the limits of the autonomy of each committee, as well as to establish the decision rules in the aggregation of results. It is worth emphasizing that, once these issues are defined, the result is highly promising, and it will be up to the senior management to follow the process and direct their efforts toward future scenarios and strategic actions for the organization.

\section{Final considerations}

The organizational decision-making process is complex, and many variables need to be considered. In addition, the whole process needs to be aligned with the operational rules established by the senior management.

The financial sector is characterized a strategic nature and significant risk. Therefore, the proposed model presents a path for organizations that seek to pursue their strategic objectives, centered on the computerization and independence of decision-makers, 
from values to action. This structure helps decision-makers in the process of goal visualization and analysis and make decisions without compromising organizational goals. In general terms, the adoption of the proposed structure and procedure facilitates decision-making, which becomes more straightforward and reliable, thus supporting decision-makers, committees, and senior management without compromising the proponent's credit. Knowing the process and the rules, the proponent can facilitate the access to credit, thus preserving the relationships established within the cooperative system.

The proposed model was applied to real organizational problems in the context of a credit cooperative. From the operational point of view, the main difficulty is that several variables are imposed by the specific organizational environment, including natural, legal, cultural, and technological variables. This variability represents the main limitation of this study: the application and definition of the model are focused on the credit cooperative environment, with its particularities and specific concepts. However, the structuring of the proposed model can be easily adapted to other organizations, respecting their specific operational and strategic features. Future research should focus on the consequences of decisions based on the analysis of different sets of specific criteria. The proposed model may easily involve new variables, thus allowing easy application to other organizational fields.

Abbreviations

BSC: Balanced Scorecard; MCDA: Multiple-Criteria Decision Analysis; SCA: Strategic Choise Approach;

SODA: Development and Analysis of Strategic Options; SSM: Soft Systems Methodology; UA: Unity of Attendance; VFT: The value-centered thinking; VPN: Virtual Private network

Acknowledgments

The authors appreciate receiving funding from the Brazilian Research Council (CNPq) to support the research contained in this paper.

Funding

Brazilian Research Council (CNPq) - Process: 309143/2014-4

Availability of data and materials

The data used for analysis and research findings are presented in the tables of the article itself. Complementary data can not be made available due to legal and confidentiality issues, guided by the research organization.

Authors' contributions

PCS contributed with the application of research and discussion of content with the organization. PCS and DCM contributed to the development of the text, interpretation of data and formatting of the research. Both authors read and approved the final manuscript.

Competing interests

The authors declare that they have no competing interests.

\section{Publisher's Note}

Springer Nature remains neutral with regard to jurisdictional claims in published maps and institutional affiliations.

Received: 8 February 2018 Accepted: 21 January 2019

Published online: 07 February 2019

References

Adla A, Zarate P, Soubie JL (2010) A Proposal of Toolkit for GDSS Facilitators. Group Decis Negot 20:57-77

Angilella S, Mazzù S (2017) A credit risk model with an automatic override for innovative small and medium-sized enterprises. J Oper Res Soc:1-17. https://doi.org/10.1080/01605682.2017.1411313.

Arthur KNA (2017) Financial innovation and its governance: cases of two major innovations in the financial sector. In: Financial innovation, vol 3, p 10. https://doi.org/10.1186/s40854-017-0060-2

Balanced Scorecard Institute. Página da internet: https://www.balancedscorecard.org/BSC-Basics/About-the-BalancedScorecard. Acesso em 05 de maio de 2017, às 12:57

Basar A, Kabak O, Topcu I (2017) A decision support methodology for locating Bank branches: a case study in Turkey. Int J Inform Tech Decis Mak 16(01):59-86 
Caiani A, Godin A, Caverzasi E, Gallegati M, Kinsella S, Stiglitz JE (2016) Agent based-stock flow consistent macroeconomics: towards a benchmark model. J Econ Dyn Control 69:375-408

Checkland P (2000) Soft Systems Methodology: A Thirty Year Retrospective Systems Research and Behavioral Science. Syst. Res. 17 , S11 - S58 (2000). https://doi.org/10.1002/1099-1743(200011)17

Collier D, Norden D (1992) Strategic choice models of political change in Latin America. Comp Polit 24(2):229-243. https:// doi.org/10.2307/422280

Delbecq AL, Van de Ven AH, Gustafson D (1975) Group Techniques for Program Planning; a guide to nominal group and Delphi processes. Scott Foresman and Company, Glenview ISBN 0-673-07591-5

Diller C, Oberding S (2017) Der «Strategic Choice Approach»: ein in Deutschland unterschätzter Methodenbaukasten für die Raumplanung, disP. Plan Rev 53(2):94-108 https://doi.org/10.1080/02513625.2017.1341200

Eden, C., Ackerman, F., 1998. Making Strategy: The Journey of Strategic Management. Sage, London. https://doi.org/10.4135/ 9781446217153

Friend JK (1992) New directions in software for strategic choice. Eur J Oper Res 61:154-164. North Holland

Friend JK (2004) Community planning for rural education in South Africa. Eur J Oper Res 152:p684-p695

Friend JK, Hickling A (1997) Planning under Pressure: The Strategic Choise Approach, 2nd edn. Pegamon, Oxford (1 ${ }^{\text {st }}$ ed Tavistock Publications, London, 1969)

Friend JK, Power JM, Yewlett CJL (1974) Public planning: the intercorporate dimension. Tavistock publications, Londres

Jongsawat N, Premchaiswadi W (2011) A study of two different experimental settings for group awareness information in a web-based group decision support system. Int J Inform Technol Decis Mak 10(2):231-268

Khakee A, Strömberg K (1993) Applying future studies and the strategic choice approach in urban planning. Journal of the operational research society. J Oper Res Soc 44:213-224. https://doi.org/10.1057/jors.1993.46

Keeney, Ralph (1996) Value-focused thinking: Identifying decision opportunities and creating alternatives. European Journal of Operational Research 92 (3):537-549. https://doi.org/10.1016/0377-2217(96)00004-5

Lake DA, Powell R (1999) Strategic choice and international relations. Princeton University Press. ISBN: 9780691026978

Leggett, C. J. Strategic Choise and the transformation of Singapore's industrial relations (2005). https://research-repository. griffith.edu.au/handle/10072/365411

Levino NDA, Morais DC (2013) "Applying strategic choice approach for decision making of watersheds committees". IEEE international conference on systems, Man and Cybernetics, pp 38-43

Lin CT, Lee C (2010) Fuzzy group decision making in pursuit or a competitive marketing strategy. Int J Inform Technol Decis Mak 09(2):281-300

Lin Z, Whinston AB, Fan S (2015) Harnessing internet finance with innovative cyber credit management. Financ Inovation 1(5) https://doi.org/10.1186/s40854-015-0004-7

Mingers J, Rosenhead J (2004) Problem structuring methods in action. Eur J Oper Res 152:530-554

Mustafá F, Khursheed A, Fatima M (2018) Impact of global financial crunch on financially innovative microfinance instituitions in South Asia. Financ Innovation 4:13

Nutt PC (1984) Planning methods: For health and related organizations. John Wiley \& Sons, Australia

Shelby AN (1991) Applying the Strategic Choice Model to Motivational Appeals: A Theoretical Approach. Int J Bus Comun 28(3):187-212

Sirbiladze G, Khustshivili I, Badagadze O, Kapanadze M (2016) More precise decision-making methodology in the temporalized body of evidence. Application in the information technology management. Int J Inform Technol Decis Mak 15(6):1469-1502

Su ZX (2011) A hybrid fuzzy approach to fuzzy multi-Attibute group decision making. Int J Inform Technol Decis Mak 10(4): $695-711$

Sutton A, Hickling A, Friend J (1986) The strategic choice approach to managing uncertainty. In: Wilkin L (ed) The Management of Uncertainty: approaches, methods and applications. NATO ASI series (D: Behavioural and social sciences), vol 32. Springer, Dordrecht

Thillaigovindan N, Shanti SA, Naidu V (2016) New method for solving a general multiple Critéria decision making problem under risk in fuzzy environment. Int J Inform Technol Decis Mak 15(5):1157-1179

Todella E, Lami IM, Armando A (2018) Experimental use of strategic Choise approach (SCA) by individuals as an architectural design tool. Group Decis Negot:1-6

Zhou S (2017) A large Group Decision-Making Method Based on Fuzzy Preference Relation. Int J Inform Technol Decis Mak 16(3):881-897

Zopounidis C (1999) Multicriteria decision aid in financial management. Eur J Oper Res 119:404-415

Zopounidis C, Doumpos M (2002) Multi-criteria decision aid in financial decision making: methodologies and literature review. J Multicrit Decis Anal 11:167-186. https://doi.org/10.1002/mcda.333

Zopounidis C, Galariotis E, Doumpos M, Sarri S, AndriosopouloS K (2015) Multiple criteria decision aiding for finance: an updated bibliographic survey. Eur J Oper Res 247(2):339-348. 